\title{
Methodology of the 2009 Survey on Living with Chronic Diseases in Canada-hypertension component
}

\author{
A. S. Bienek, MHA (1); M. E. Gee, MSc (1); R. P. Nolan, PhD (2); J. Kaczorowski, PhD (3); N. R. Campbell, MD (4); \\ C. Bancej, PhD (1); F. Gwadry-Sridhar, PhD (5); C. Robitaille, MSc (1); R. L. Walker, MSc (6); S. Dai, MD (1)
}

This article has been peer reviewed.

\begin{abstract}
Introduction: The Survey on Living with Chronic Diseases in Canada-hypertension component (SLCDC-H) is a 20-minute cross-sectional telephone survey on hypertension diagnosis and management. Sampled from the 2008 Canadian Community Health Survey (CCHS), the SLCDC-H includes Canadians (aged $\geq 20$ years) with self-reported hypertension from the ten provinces.
\end{abstract}

Methods: The questionnaire was developed by Delphi technique, externally reviewed and qualitatively tested. Statistics Canada performed sampling strategies, recruitment, data collection and processing. Proportions were weighted to represent the Canadian population, and $95 \%$ confidence intervals (CIs) were derived by bootstrap method.

Results: Compared with the CCHS population reporting hypertension, the SLCDC-H sample $(\mathrm{n}=6142)$ is slightly younger (SLCDC- $\mathrm{H}$ mean age: 61.2 years, $95 \%$ CI: 60.8-61.6; CCHS mean age: 62.2 years, $95 \%$ CI: 61.8-62.5), has more post-secondary school graduates (SLCDC-H: $52.0 \%$, 95\% CI: 49.7\%-54.2\%; CCHS: $47.5 \%$, $95 \%$ CI: $46.1 \%-48.9 \%$ ) and has fewer respondents on hypertension medication (SLCDC-H: $82.5 \%$, $95 \%$ CI: $80.9 \%-84.1 \%$; CCHS: $88.6 \%$, $95 \%$ CI: $87.7 \%-89.6 \%$ ).

Conclusion: Overall, the 2009 SLCDC-H represents its source population and provides novel, comprehensive data on the diagnosis and management of hypertension. The survey has been adapted to other chronic conditions-diabetes, asthma/chronic obstructive pulmonary disease and neurological conditions. The questionnaire is available on the Statistics Canada website; descriptive results have been disseminated by the Public Health Agency of Canada.

Keywords: epidemiological survey, hypertension, chronic disease, data collection, health surveys, questionnaires, Canadian Community Health Survey

\section{Introduction}

More than one in five Canadians aged over 20 years have been diagnosed with hypertension, ${ }^{1,2}$ and a further $17 \%$ of the adult population may be unaware that they have the condition. ${ }^{3}$ Elevated blood pressure is a major etiological factor for cardiovascular diseases, but it can be effectively controlled with lifestyle changes in physical activity, diet, sodium intake, alcohol use, weight management and tobacco use, or through pharmacotherapy, when required. ${ }^{4}$ Despite this, about $33 \%$ of Canadians diagnosed with hypertension have blood pressure levels that are not well-controlled. ${ }^{3}$ Improv- ing the understanding of the knowledge, attitudes and behaviours of Canadians diagnosed with hypertension would support the development and the enhancement of programs for blood pressure control.

In 2009, the Public Health Agency of Canada (PHAC) conducted the Survey on Living with Chronic Diseases in Canadahypertension component (SLCDC-H) to determine how Canadians live with and manage their hypertension. The 20-minute survey was the first survey administered to a nationally representative sample of Canadians diagnosed with a specific chronic condition, providing new variables that could be used to monitor and report on health-related indicators. This paper describes the objectives and methodology of the 2009 SLCDC-H and examines the representativeness of the final sample.

\section{Methods}

\section{Survey objectives}

PHAC initiated the SLCDC in 2006 to: (1) assess the impact of chronic conditions on quality of life of individuals and their families; (2) collect information on how people manage their chronic conditions; (3) identify the use of interventions for chronic condition management among people living in the community; (4) identify health behaviours that influence disease outcomes; and (5) examine barriers to self-management of chronic conditions. PHAC selected hypertension

\section{Author references:}

1. Public Health Agency of Canada, Ottawa, Ontario, Canada

2. University Health Network, Toronto, Ontario, Canada

3. Département de médecine familiale et médecine d'urgence, Université de Montréal, Centre de recherche du CHUM, Hôpital Notre-Dame, Montréal, Quebec, Canada

4. Departments of Medicine, Community Health Sciences and Physiology and Pharmacology, Libin Cardiovascular Institute of Alberta, University of Calgary, Calgary, Alberta, Canada

5. Lawson Health Research Institute, University of Western Ontario, London, Ontario, Canada

6. Department of Community Health Sciences, University of Calgary, Calgary, Alberta, Canada

Correspondence: Asako S. Bienek, Public Health Agency of Canada, 785 Carling Avenue, AL: 6806A, Ottawa, ON K1A 0K9; Tel.: 613-952-6163; Fax: 613-941-2057;

Email: Asako.Bienek@phac-aspc.gc.ca 
and arthritis for the first iteration of the SLCDC after taking into consideration the importance to public health, the existence of complementary national surveillance work, and the prevalence and sample size of several chronic conditions. After consulting with Statistics Canada, it was determined that ethics approval was not required for this survey because physical measures were not being taken. No privacy or confidentiality risks, as governed by the Privacy Impact Assessment policy, were identified, and the Chief Statistician of Statistics Canada allowed the survey to proceed.

\section{Survey content development}

In 2007, PHAC collaborated with the Canadian Hypertension Education Program (CHEP) to create a Working Group with expertise in hypertension or survey development and validation. The Working Group developed the telephone-administered questionnaire used in the cross-sectional survey. Questions were derived from publicly available population surveys including the core, theme and optional contents of the various cycles of the Canadian Community Health Survey (CCHS); ${ }^{5}$ Cycle 4 of the Canadian National Population Health Survey (NPHS) ${ }^{6}$ the blood pressure and cardiovascular disease questionnaires of the American National Health and Nutrition Examination Survey (NHANES) 2005-06; ${ }^{7}$ the American Harris Interactive Survey-Hypertension Education $(2007)^{8}$ as well as surveys on specific content areas such as physical activity or diet. Peerreviewed literature was consulted for other instruments and well-known scales, such as general self-efficacy scales or the Morisky medical adherence scale. ${ }^{9-11}$ Certain questions on blood pressure management and monitoring were adapted based on consultations with experts and from existing national guidelines, including those by $\mathrm{CHEP}^{12,13}$, the National Institutes of Health, ${ }^{14}$ and the National Cholesterol Education Program in the United States. ${ }^{15}$

A preliminary review determined if questions were age- and population-appropriate, amenable to telephone administration and within the scope of the SLCDC while general enough to be reproducible to other chronic conditions and in future iterations.
Using the CCHS as a guide, the retained questions were organized by theme and reformatted with a focus on sequencing and skip patterns, standardization of questions, categories and ranges, and consistent use of language and narrative point of view. Response bias was considered when removing leading or repetitive questioning. The time constraints of a telephone interview and respondent fatigue also dictated the length of the survey.

A Delphi panel approach was used to reach consensus on content. In general, those questions to which answers would be difficult to analyze or interpret were deleted. Similarly, those which would be difficult to translate into actionable recommendations were also deleted. This included concepts that (1) were already targeted on the main CCHS and thus obtainable through linkage (e.g. nutrition or physical activity); (2) were too lengthy to be adequately addressed (e.g. health utility, stages of change); (3) required detailed explanation (e.g. expectations of selfefficacy); or (4) would yield response categories too small to analyze. Final content of the English survey was translated into French to allow for implementation in Canada's two official languages, and translated content was verified for accuracy.

\section{External review}

Using a working draft of the questionnaire, 15 CHEP members $30 \%$ response rate) reviewed the survey and supplied detailed feedback, which was used to confirm key content areas and addressed potential gaps. Some of their recommendations were outside the scope of the survey, for example, 24-hour food recall, use of speciality clinics, ambulatory blood pressure monitoring, exploration of other macrovascular conditions, and global cardiovascular risk. However, other areas were added or expanded, including usefulness and availability of written educational material on hypertension, knowledge of key issues, and barriers to adherence to lifestyle changes.

\section{Qualitative testing}

Statistics Canada conducted qualitative testing of both English and French surveys for clarity, face validity, question flow, and ease of administration and response using a sub-sample of respondents with a current or past diagnosis of hypertension (regardless of pharmacotherapy for hypertension), randomly drawn from about 10000 CCHS 2007 respondents. Every effort was made to obtain as diverse a sample as possible in terms of age, sex, level of education and income, and place of residence (city core versus greater metropolitan area). Verbal consent was obtained during screening, and the participants were informed that the interview would be recorded and staff would be observing them.

One hour was allotted for individual faceto-face interviews. Of the 16 interviews scheduled, 13 were successfully completed (eight in English, five in French). During the interview, staff made general observations on participants' reactions to the content and their willingness and ability to provide responses. The interviewers probed participants on their blood pressure measurements and adherence to medication, and also asked for their overall feedback on the content of the survey. Due to the small sample, results were used for their qualitative input and were not considered statistically representative. The time taken to administer the questionnaire averaged between 30 and 40 minutes, suggesting the need to reduce the content by an additional 15 minutes (dictated by the longer French version). Also, question order was revised to improve the flow, sensitive questions and reference periods were modified, language was simplified, terminology and translations were clarified and answer keys and skips were edited to better reflect actual responses.

\section{Final questionnaire}

The final 20-minute questionnaire included eight hypertension-specific modules (Table 1) as well as entry and exit components (totalling five minutes) and a general health module. The full questionnaire is available on the Statistics Canada website (www.statcan.gc.ca/ imdb-bmdi/instrument/5160_Q4_V1-eng.htm). The final survey was implemented with a computer-assisted telephone interview 
TABLE 1

Modules of the 2009 SLCDC-H questionnaire

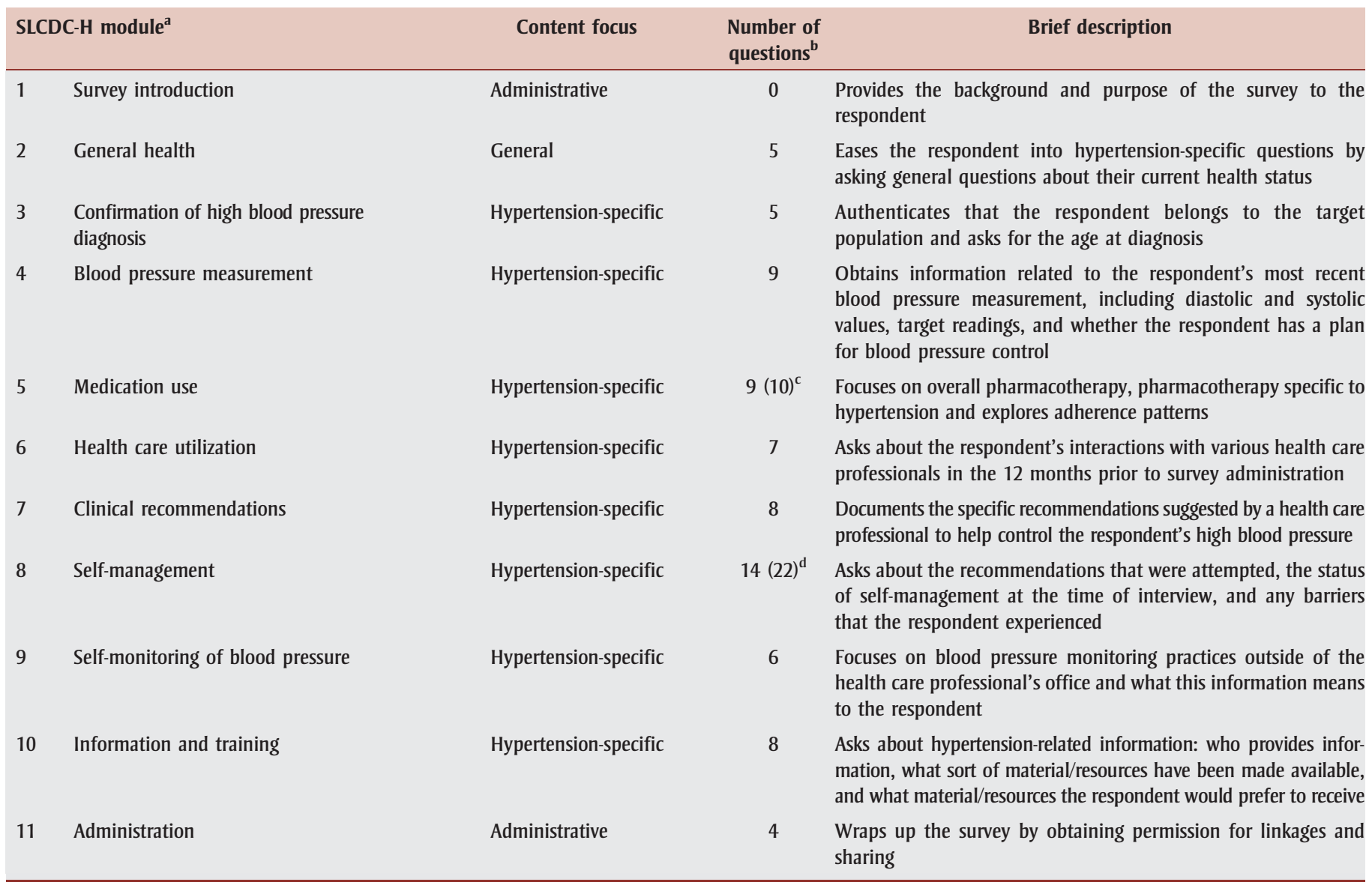

Abbreviations: CCHS, Canadian Community Health Survey; SLCDC-H, Survey on Living with Chronic Diseases in Canada - Hypertension Component.

a The 11 modules associated with the SLCDC-H are linked to the 2008 CCHS, resulting in a total of 87 modules available for analysis.

b The number of questions delivered to each respondent depends on skip patterns and the eligibility of the respondent for particular questions.

c Although 9 questions make up this module, one is split into two parts, resulting in a total of 10 questions.

${ }^{d}$ Although 14 questions make up this module, several are split into parts, resulting in a total of 22 questions.

(CATI) application, which facilitated consistent survey administration. The CATI application controlled the logical flow of questions, specified ranges for valid answers, identified minimum and maximum values for quantitative responses and provided standardized procedures for nonresponse. $^{16}$ End-to-end testing on the application was done in a simulated collection environment.

\section{Target population}

The target population for the SLCDC-H was the Canadian adult ( $\geq 20$ years) population diagnosed with hypertension, with the CCHS used as the sampling frame. The CCHS is a cross-sectional national survey that has provided selfreported data on health status, health care utilization and health determinants in the Canadian population since $2000 .{ }^{17-19}$ The SLCDC-H obtained detailed information on the population with hypertension, while permitting linkage back to the main CCHS for additional socio-demographic and risk factor data.

The eligible population for the 2009 SLCDC-H included Canadians living in privately occupied dwellings in the ten provinces. Residents of the three northern territories were not surveyed due to insufficient sample sizes, which lead to the inability to properly weight findings to represent all residents. Also excluded from the CCHS, and subsequently from the 2009 SLCDC-H, were full-time members of the Canadian Forces, people living on Indian reserves or Crown lands, and residents of institutions or of certain remote regions (together representing less than $2 \%$ of the target population). ${ }^{16,18}$

To identify the population for the SLCDC$\mathrm{H}$, a standard module in the CCHS that asks about chronic conditions diagnosed by a health care professional and lasting six months or more was used. Respondents who were 20 years of age or older who answered "yes" to the questions "Do you have high blood pressure?" or "In the past month, have you taken any medicine for high blood pressure?" (total of $\mathrm{n}=17$ 437) were eligible. $^{16}$ Women with pregnancyinduced hypertension were excluded. Only the CCHS respondent, not the whole household, was eligible for selection. Proxy interviews were not permitted. 


\section{Sampling strategy}

Sampling analyses were performed on several cycles of the CCHS during the development of the SLCDC. The multistage cluster sampling strategy applied in all these instances was similar. To begin, the raw unweighted data of all available respondents with hypertension were allocated to various domains (sex; age group: 20-44, 45-64, 65-74, $\geq 75$ years; province; region: Atlantic, Quebec, Ontario, Prairies, British Columbia), and combinations thereof, to ensure that final numbers would be sufficient by these key domains. Administration of the survey to this full population was not feasible. In addition, some of these respondents were required for the arthritis component of the SLCDC; because both surveys were to be delivered concurrently, respondents allocated to one questionnaire became ineligible for the other, regardless of whether they had both conditions. As such, the raw data were filtered within each domain to create a raw sample of respondents with hypertension available for the SLCDC-H. During this process, sample allocation was based on relative proportions of arthritis and hypertension in the main survey to ensure that cell sizes for both surveys were large enough to analyze. In some domains, the full raw counts were retained to ensure a sufficient sample.

Subsequently, the raw sample was again adjusted, this time taking into account probable sample loss. The response rate was estimated to be $70 \%$, allotting about $10 \%$ of loss to failure in recruitment or from the denial of permission for sharing/ tracing of data and the other $20 \%$ due to non-response. Based on this, each domain was adjusted by a factor of 0.70 . This produced the number of respondents expected to be available for survey administration and was the basis for further sampling analyses below.

At the onset of SLCDC development, the 2005 CCHS file was used to determine the feasibility of obtaining sufficient samples for both arthritis and hypertension surveys concurrently. Analyses focused on estimating the minimum sample size required to produce reliable estimates by domain. For hypertension, the minimum sample size was determined to be 1324 , assuming a fixed design effect of 2.8 for age group and sex, where the sample variance was about 2.8 times larger than it would have been if the survey was based on random selection. For province and region, the fixed design effect was set to 3 . Results from this sampling analysis confirmed that sufficient populations were available for independent surveys on arthritis and hypertension.

Closer to survey administration, the 2007 CCHS file was used to estimate the reportability of findings. The goal was to determine the minimum prevalence required, by domain, to achieve a pre-set coefficient of variation (CV) of $16.5 \%$. Although the maximum CV is typically set at $33.3 \%$, beyond which data would be considered unreportable, the CV was targeted to a more conservative $16.5 \%$ or less so as to provide reliable estimates. Based on this analysis, estimates would be reliable for most age groups and by sex, but only national or regional estimates would be reportable.

Finally, to identify the eligible 2009 SLCDC-H population, respondents were pulled from verified data in the $2008 \mathrm{CCHS}$ file. Numbers of selected eligible respondents were inflated where possible (from $\mathrm{n} \approx 6000$ respondents to $\mathrm{n}=9055$ ) to lessen the effect of non-response and outof-scope cases. Additional details, including a distribution of the eligible sample by domain, can be found at http://www. statcan.gc.ca/imdb-bmdi/document/5160_ D5_T1_V1-eng.htm.

\section{Recruitment, data collection and processing}

Recruitment for the 2009 SLCDC-H began in mid-January 2009 with the mailing of introductory letters to selected respondents, followed by telephone interviews. Measures taken to maximize response rates included mailing supportive letters, offering convenient interview times, tracing respondents who moved or had invalid phone numbers, and providing the interview in either French or English, depending on the respondent's preference. ${ }^{16}$ The interviewers were required to disclose the survey title, purpose and authority, that the survey was voluntary and that respondent confidentiality was protected. Respondents provided informed verbal consent to participate.

Data collection began in February 2009 and lasted three months. Between April and December 2009, data underwent processing, estimation and documentation. For respondents who agreed to link and share the surveys, the 2009 SLCDC-H was linked to the 2008 CCHS. To preserve respondent confidentiality, all personal identifiers were removed from the share-link file. Data were ready for use in December 2009 and were made available to PHAC, Health Canada and provincial health ministries. Researchers and third parties are able to access master files through university-based Research Data Centres run by Statistics Canada (http:// www.statcan.gc.ca/rdc-cdr/process-eng.htm).

\section{Data analysis}

For estimates to be representative of the target population, survey weights were derived. Based on the final SLCDC-H sample, weight values corresponded to the number of people in the Canadian population represented by each respondent. Survey weights and bootstrap replicates were further adjusted to account for out-ofscope cases, non-responses and cases in which the respondent did not agree to share their data. ${ }^{16,20}$ To compare the characteristics of respondents with hypertension between the two surveys, the 2008 CCHS population was limited to adults aged 20 years or older, and excluded the territories and pregnant women. Estimates were weighted using appropriate weights for each survey, and the bootstrap resampling method was applied to derive confidence intervals (CIs) using SAS Enterprise Guide version 4 (SAS Institute Inc., Cary, NC, US). Data reporting was subject to reliability guidelines stipulated by Statistics Canada regarding rounding and sampling error. ${ }^{16}$

\section{Results}

\section{Final sample population}

Figure 1 illustrates the flow of respondent participation in the 2009 SLCDC-H. A total of 17437 respondents who reported being diagnosed with high blood pressure in the 
FIGURE 1

Respondent participation in the 2009 SLCDC- ${ }^{\mathrm{a}}$

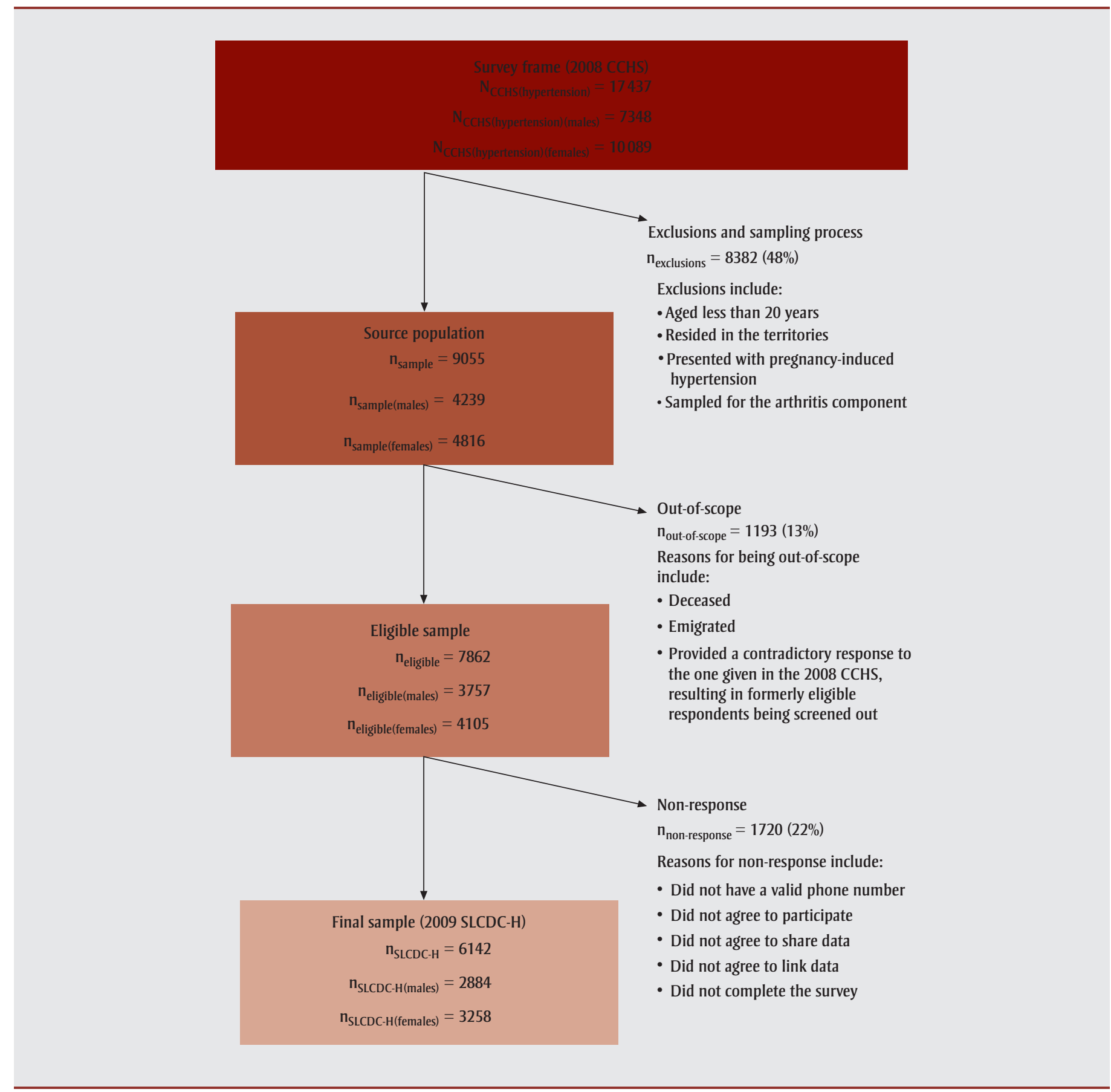

Abbreviations: CCHS, Canadian Community Health Survey; SLCDC-H, Survey on Living with Chronic Diseases in Canada - Hypertension Component.

${ }^{\mathrm{a}}$ Numbers are unweighted.

2008 CCHS formed the survey frame. Anticipated loss between the survey frame and the final 2009 SLCDC-H sample included loss based on pre-set exclusion criteria (aged < 20 years; resided in the territories; presented with pregnancyinduced hypertension only) and from contacted cases who were found to be out-of-scope (deceased; emigrated; false positive; false negative). In this case, the proportion of out-of-scope cases in the SLCDC-H (13\%) exceeded anticipated estimates (10\%), largely due to a misclassification of respondents. False positives occurred if respondents pooled for the SLCDC-H later claimed not to have high blood pressure; among other reasons, this could have been due to an emphasis on a diagnosis by a health care professional, eliminating those who self-diagnosed their condition or misinterpreted the original question. False negatives may have resulted in a loss of respondents who actually had hypertension, but who 
responded "no" to screening questions; among other reasons, this could have been intentionally done to avoid participation in the SLCDC-H.

During the development, administration or processing of the survey, eligible respondents may have also been lost if they (1) were pooled into the sample for the arthritis component; (2) were unwilling to be contacted again after responding to the 2008 CCHS; (3) were repeatedly absent for the interview; (4) refused to respond to the survey; or (5) refused linkages or use of their data. The hit rate, or the eligible sample that was contacted for interview $(\mathrm{n}=7862)$ as a proportion of the source population ( $\mathrm{n}=9055)$, varied from $75.2 \%$ in men aged 20 to 44 years to $93.1 \%$ in those aged 65 to 74 years. ${ }^{16}$ Similarly, the hit rate in women was lowest in the youngest age group $(51.1 \%)$ and highest in the 65 - to 74-year age group (94.7\%). ${ }^{16}$ The response rate, or the final sample who completed the survey ( $n=6142$ ) as a proportion of the eligible sample ( $\mathrm{n}=7862$ ), varied from a low in the 20- to 44-year age group (men: $65.6 \%$; women: $71.7 \%$ ) to a high in the 65- to 74-year age group (men: $79.7 \%$; women: $82.1 \%) .{ }^{16}$ The final achieved sample available for analysis was 6142, representing an overall response rate of $78.1 \%$.

\section{Population characteristics}

Table 2 shows selected socio-demographic and health characteristics of respondents aged 20 years or older reporting hypertension in the 2008 CCHS share file compared to the population of the 2009 SLCDC-H. The 2009 SLCDC-H was a representative sample of the CCHS population for ethnicity, body mass index, smoking status, self-reported diabetes, availability of a regular medical doctor, and number of medical consultations in the past year. A few indicators were significantly different (i.e. $p$ value $<0.05$; CIs did not overlap). The SLCDC-H population had a mean age of 61.2 years $(95 \% \mathrm{CI}$ : 60.8-61.6) compared with 62.2 years $(95 \%$ CI: 61.8-62.5) in the 2008 CCHS, a higher proportion of respondents with postsecondary graduation (SLCDC-H: $52.0 \%$, 95\% CI: $49.7 \%-54.2 \%$; CCHS: $47.5 \%$, $95 \%$ CI: $46.1 \%-48.9 \%$ ), and a smaller proportion of respondents reporting pharmacotherapy for hypertension (SLCDC-H: $82.5 \%$, 95\% CI: $80.9 \%-84.1 \%$; CCHS: $88.6 \%$, 95\% CI: $87.7 \%-89.6 \%)$. Significant differences based on a $p$ value of less than .05 were seen for some categories within other variables, including male sex, poor/fair self-rated health, "active" physical activity level, income, and self-reported heart disease and stroke. However, in these instances, CIs overlapped and the ratio of proportions was close to 1 (ranging from 0.87 to 1.27 ).

\section{Survey response characteristics}

An unweighted frequency analysis found that most questions had less than $1 \%$ missing data (not shown). Although "don't know" (DK) and "refusal” (R) options were allowed on most questions, these response categories were not read aloud. Questions with a higher prevalence of DK, $\mathrm{R}$, or "not stated" answers were clustered around themes. For instance, respondents were asked to report their systolic and diastolic blood pressure levels. Poor recollection was expected, and $18.0 \%$ and $22.3 \%$ of respondents did not state a valid answer for systolic and diastolic blood pressure levels, respectively. Nevertheless, these questions were intentionally administered to provide baseline information on awareness of and knowledge about hypertension at the population level.

Most response ranges and distribution by category were reasonable. However, the most prevalent response for some general health questions with a five-category response scale (“excellent”; “very good”; "good"; “fair”; “"poor”) was "good," that is, a central tendency. This suggests that the format of some scales could have contributed to neutral answers.

\section{Discussion}

The presented sample survey covers a wide range of issues affecting Canadians with hypertension, such as awareness of blood pressure levels, self-monitoring practices, clinical recommendations, pharmacotherapy, and strategies for and barriers to self-management. The SLCDC-H has generated several findings to date, and has quantified a robust profile of Canadians with hypertension.

Specific findings included a high level of antihypertensive pharmacotherapy in Canada $(82.5 \%$ of adults with hypertension), with an additional $10 \%$ of the population controlling their hypertension by changes in lifestyle alone. ${ }^{21,22}$ For those controlling their hypertension with medication, neither an increasing number of medications nor the frequency of dosing were associated with non-adherence. ${ }^{21}$ Strategies based on lifestyle change were reported by an impressive number of respondents-the majority-but less than half performed these actions consistently, and a disconcerting proportion reported not receiving advice from their health care professional about lifestyle change strategies. ${ }^{22-24}$ Further, Gee et al. ${ }^{24}$ noted that barriers to ceasing negative health behaviours differed from barriers to initiating positive behaviours.

Profiles of higher risk sub-groups were generated, including a description of those at risk of not engaging in lifestyle behaviour changes or those less likely to monitor their blood pressure outside of a health care professional's office. ${ }^{24,25}$ Various negative impacts were associated with a respondent's sense of poor control over their hypertension and when a health care professional does not offer advice or education on lifestyle management. ${ }^{23,26}$ Findings such as these provide direction for targeted interventions.

Overall, the 2009 SLCDC-H represents its source population, though respondents to the SLCDC-H are somewhat younger, better educated, and less likely to be pharmacologically treated for their hypertension. The effects of this potential selection bias may be that data represent a newly diagnosed, potentially healthier group, living with hypertension for a shorter period of time. Based on $p$ values alone, other statistically significant differences exist, but CIs overlap and the relative magnitude of one proportion compared to the other is close to 1 . In short, despite significant $p$ values, meaningful differences may not exist and users 
TABLE 2

Comparison of characteristics between source population with hypertension (2008 CCHS) and respondents to the 2009 SLCDC-H

\begin{tabular}{|c|c|c|c|c|c|c|}
\hline & \multicolumn{4}{|c|}{ Population with hypertension, $\geq 20$ years } & \multirow{3}{*}{$\underset{\text { value }^{\mathrm{d}}}{p}$} & \multirow{3}{*}{$\begin{array}{c}\text { Ratio } \\
\text { CCHS:SLCDC-H }\end{array}$} \\
\hline & \multicolumn{2}{|c|}{2008 CCHS $\left(N=13896^{a}\right)$} & \multicolumn{2}{|c|}{2009 SLCDC-H $(\mathrm{N}=6142)$} & & \\
\hline & $n^{\mathbf{b}}$ & $\%^{\mathrm{c}}(95 \% \mathrm{Cl})$ & $\mathbf{n}^{\mathbf{b}}$ & $\%^{\mathrm{c}}(95 \% \mathrm{Cl})$ & & \\
\hline \multicolumn{7}{|l|}{ Sex } \\
\hline Male & 5961 & $48.2(47.1-49.4)$ & 2884 & $46.7(45.1-48.4)$ & $.03^{\mathrm{e}}$ & 1.03 \\
\hline \multicolumn{7}{|l|}{ Age, years } \\
\hline$\geq 65$ & 7503 & $44.5(43.4-45.6)$ & 3484 & $40.8(39.2-42.4)$ & $<.0001^{\mathrm{f}}$ & 1.09 \\
\hline Mean & & $62.2(61.8-62.5)$ & & $61.2(60.8-61.6)$ & $<.0001^{\mathrm{f}}$ & 1.02 \\
\hline \multicolumn{7}{|l|}{ Ethnicity } \\
\hline White & 12535 & $85.3(83.8-86.8)$ & 5676 & $86.8(84.6-89.0)$ & .13 & 0.98 \\
\hline$<$ Secondary school graduation & 4419 & $25.9(24.7-27.2)$ & 1798 & $23.3(21.5-25.1)$ & $.001^{\mathrm{e}}$ & 1.11 \\
\hline Secondary school graduation & 2170 & $16.8(15.7-17.9)$ & 961 & $17.6(15.7-19.4)$ & .37 & 0.95 \\
\hline Some post-secondary & 772 & $6.2(5.4-6.8)$ & 358 & $7.2(5.9-8.4)$ & .06 & 0.86 \\
\hline Post-secondary graduation & 6177 & $47.5(46.1-48.9)$ & 2988 & $52.0(49.7-54.2)$ & $<.0001^{\mathrm{f}}$ & 0.91 \\
\hline \multicolumn{7}{|l|}{ Total household income, $\$$} \\
\hline$<15,000$ & 1247 & $7.1(6.4-7.8)$ & 473 & $6.1(5.0-7.2)$ & $.04^{\mathrm{e}}$ & 1.16 \\
\hline $15,000-29,999$ & 3106 & $19.4(18.3-20.5)$ & 1410 & $19.5(17.7-21.4)$ & .85 & 0.99 \\
\hline $30,000-49,999$ & 2846 & $21.9(20.7-23.1)$ & 1351 & $20.0(18.2-21.7)$ & $.02^{\mathrm{e}}$ & 1.10 \\
\hline $50,000-79,999$ & 2526 & $24.8(23.2-26.3)$ & 1255 & $23.7(21.6-25.8)$ & .29 & 1.05 \\
\hline$\geq 80,000$ & 2100 & $26.8(25.3-28.4)$ & 1058 & $30.7(28.0-33.4)$ & $.0007^{\mathrm{e}}$ & 0.87 \\
\hline 25-29 (overweight) & 5103 & $39.3(37.8-40.8)$ & 2415 & $38.4(36.1-40.8)$ & .42 & 1.02 \\
\hline$\geq 30$ (obese) & 4098 & $30.9(29.6-32.3)$ & 1805 & $33.0(30.6-35.4)$ & .05 & 0.94 \\
\hline \multicolumn{7}{|l|}{ Physical activity level } \\
\hline Active & 2286 & $16.8(15.8-17.8)$ & 1177 & $18.5(16.9-20.1)$ & $.02^{\mathrm{e}}$ & 0.91 \\
\hline Moderately active & 3157 & $22.8(21.6-23.9)$ & 1490 & $23.2(21.3-25.0)$ & .61 & 0.98 \\
\hline Inactive & 8022 & $56.8(55.4-58.2)$ & 3472 & $58.4(56.2-60.5)$ & .11 & 0.97 \\
\hline \multicolumn{7}{|l|}{ Smoking status } \\
\hline Current daily & 1984 & $14.1(13.2-15.0)$ & 842 & $14.0(12.5-15.5)$ & .90 & 1.01 \\
\hline Current occasional & 311 & $2.3(1.8-2.8)$ & 149 & $3.1(2.1-4.2)$ & .08 & 0.74 \\
\hline Non-smoker & 11564 & $83.2(82.2-84.3)$ & 5149 & $82.9(81.1-84.7)$ & .64 & 1.00 \\
\hline \multicolumn{7}{|l|}{ Co-morbidities } \\
\hline Diabetes & 2830 & $20.3(19.1-21.5)$ & 1172 & $19.2(17.0-21.3)$ & .21 & 1.06 \\
\hline Heart disease & 2590 & $16.3(15.4-17.3)$ & 1077 & $14.7(13.0-16.4)$ & $.03^{\mathrm{e}}$ & 1.11 \\
\hline Effects of stroke & 627 & $3.8(3.3-4.2)$ & 223 & $3.0(2.4-3.6)$ & $.006^{\mathrm{e}}$ & 1.27 \\
\hline
\end{tabular}


TABLE 2 (continued)

Comparison of characteristics between source population with hypertension (2008 CCHS) and respondents to the 2009 SLCDC-H

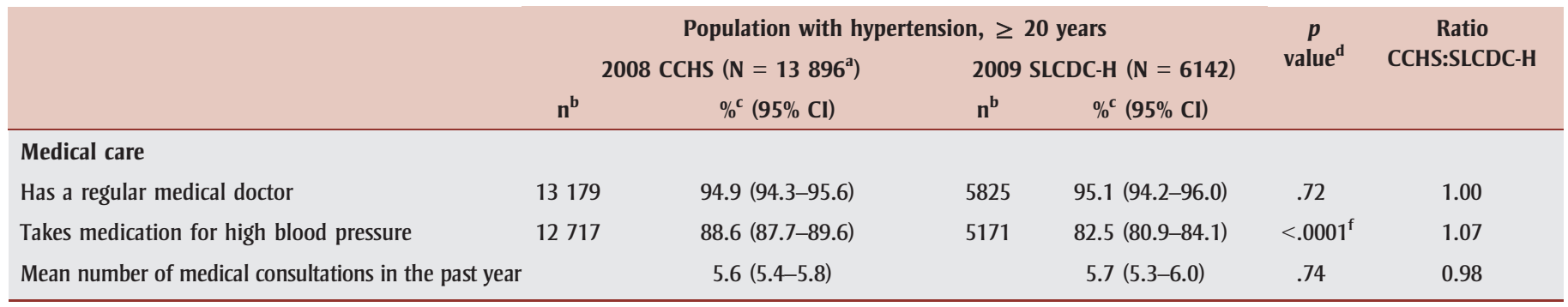

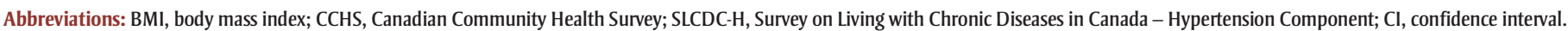

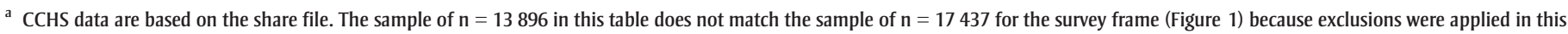
case (age $<20$ years; residents of territories; people with pregnancy-induced hypertension). Further, in this case, individuals with arthritis are retained, whereas in Figure 1 some respondents may have later been removed for the arthritis component.

b Numbers are unweighted.

c Proportions are based on weighted numbers to reflect the Canadian population living in the ten provinces.

${ }^{\mathrm{d}} p$ values are based on $z$ tests to determine significant differences between the two ratios.

e Statistically significant differences based on $p<.05$. However, it should be noted that Cls overlap and the difference between populations is small.

${ }^{f}$ Statistically significant difference based on $p<.05$; Cls do not overlap.

should decide whether this may impact their analyses.

\section{Strengths and limitations}

On a broader scope, the 2009 SLCDC-H was developed to be nationally representative. However, the representativeness of the data to the Canadian population may be limited due to the exclusion of the territories and other populations. Administrative data have shown that the age-standardized incidence rate of hypertension in the Yukon is far above the Canadian average (37.7 per 1000 population versus 25.8 ), but that the age-standardized prevalence rate is lower (17.9\% versus 19.6\%). ${ }^{1,2}$ It would be interesting to explore hypertension diagnosis and management in the Yukon. Moreover, other potentially excluded populations (e.g. specific ethnic groups) would have likely presented with different characteristics. $^{27}$ Since the SLCDC-H was only administered in two languages, it may have excluded some of the 493 (1.7\%; unweighted) participants who originally responded to the 2008 CCHS in a language other than English and French. Oversampling of vulnerable and/or ethnic populations is encouraged for future surveys.

A well-known limitation of self-reported surveys is that they are subject to various sampling and non-sampling errors, such as response bias, recall bias and non-differential misclassification. Since the objective of the survey was to understand hypertension management in those aware of their condition, the target population was based on individuals who self-reported a diagnosis of hypertension, excluding those with undiagnosed hypertension. Although the majority of Canadians with hypertension (83\%) are aware of their condition, ${ }^{3}$ the accuracy of self-reported hypertension status remains unclear. Individuals without actual diagnosis may report having the condition (false positive) while individuals who have their hypertension controlled may not report themselves as having hypertension (false negative). However, the rate of misclassification is likely lower in the SLCDC-H given that many of these cases were identified during the screening process.

Attempts were made to identify whether lifestyle changes were attributable to a diagnosis of hypertension. Nevertheless, lifestyle changes can be influenced by a number of factors outside of such a diagnosis. Another limitation of this survey is that, while linkage to the CCHS for additional variables improved efficiency, participant characteristics may have changed in the time between the surveys (averaging 8.5 months), ${ }^{26}$ leading to potential misclassification. Statistics Canada has taken measures to reduce survey errors, such as using the CATI system and extensive training of interviewers to minimize non-response. Specific to the SLCDC-H, the Lawson Health Research Institute has initiated a validation study to perform test-retest comparisons of the questionnaire in two populations with hypertension.

\section{Conclusion}

The 2009 SLCDC-H provides novel, comprehensive data on the diagnosis of hypertension and management mechanisms used by Canadians with self-reported high blood pressure. Based on the success of the first iteration of the SLCDC, the methodology and content have since been adapted to two subsequent cycles of the survey (diabetes and asthma/chronic obstructive pulmonary disease), with data released in 2011. ${ }^{28}$ The methodology was also adapted for the Survey on Living with Neurological Conditions in Canada, with data released in late $2012 .{ }^{29}$ It is anticipated that these data will create opportunities for new research, influence policy development and guide strategies to improve chronic disease prevention and control in Canada.

\section{Acknowledgements}

The authors declare that they have no competing interests. No outside funding was obtained for this study.

The survey was sponsored and developed by the Public Health Agency of Canada (Dr. Paula Stewart, Ms. Asako S. Bienek, Mr. Jay Onysko, Dr. Christina Bancej, 
Ms. Deirdre MacGuigan and Ms. Marianne E. Gee) in conjunction with Statistics Canada (Mr. Mamadou S. Diallo, Ms. Christy da Silva, Ms. Stacey Wan, Mr. Sylvain Tremblay, Mr. Vince Dale, Ms. Cathy Trainor, Ms. Cindy Bennett, Ms. MarieNoëlle Parent and Ms. Brenda Bélanger).

The SLCDC-H was developed through the contribution of time and expertise by external Working Group members: Dr. Norm R. C. Campbell (Canadian Hypertension Education Program), Dr. Femida Gwadry-Sridhar (University of Western Ontario), Ms. Robin L. Walker (University of Calgary), Dr. Janusz Kaczorowski (Université de Montréal), Dr. Michel Joffres (Simon Fraser University), Dr. Robert P. Nolan (University Health Network and University of Toronto), Dr. Patrice Lindsay (Canadian Stroke Network) and Dr. Hude Quan (University of Calgary).

\section{References}

1. Public Health Agency of Canada. Report from the Canadian Chronic Disease Surveillance System: hypertension in Canada, 2010 [Internet]. Ottawa (ON): Chronic Disease Surveillance Division; 2011 [cited 2011 Mar 3]. Available from: http://www.phac-aspc.gc.ca/cd-mc/cvd-mcv /ccdss-snsmc-2010/pdf/CCDSS_HTN_Report _FINAL_EN_20100513.pdf

2. Robitaille C, Dai S, Waters C, et al. Diagnosed hypertension in Canada: incidence, prevalence, and associated mortality. CMAJ. 2012 Jan;184(1):E49-56.

3. Wilkins K, Campbell NR, Joffres MR, et al. Blood pressure in Canadian adults. Health Rep. 2010 Mar;21(1):37-46.

4. Rabi DM, Daskalopoulou SS, Padwal RS, et al. The 2011 Canadian Hypertension Education Program recommendations for the management of hypertension: blood pressure measurement, diagnosis, assessment of risk, and therapy. Can J Cardiol. 2011 Jul-Aug;27(4):415-33.e1-2.
5. Other reference periods - Canadian Community Health Survey - annual component [Internet]. Ottawa (ON): Statistics Canada; 2011 [cited 2011 Mar 25]. Available from: http://www.statcan.gc.ca/cgi-bin/imdb /p2SV.pl?Function = getInstanceList\&SurvId $=3226 \&$ SurvVer $=1 \&$ InstaId $=15282 \&$ SDDS $=3226 \& l a n g=e n \& d b=i m d b \& a d m=8 \&$ dis $=2$

6. National Population Health Survey - household component - longitudinal (NPHS) [Internet]. Ottawa (ON): Statistics Canada; 2011 [updated 2011 Jul 20; cited 2011 Mar 23]. Available from: http://www.statcan.gc .ca/cgi-bin/imdb/p2SV.pl?Function = getSurvey \&SDDS $=3225 \&$ lang $=$ en \&db $=$ imdb\&adm $=8 \&$ dis $=2$

7. National Health and Nutrition Examination Survey - NHANES 2005-2006 [Internet]. Atlanta (GA): Centers for Disease Control and Prevention; 2011 [updated 2011 Apr 29; cited 2011 Mar 23]. Available from: http:// www.cdc.gov/nchs/nhanes/nhanes2005-2006 /nhanes05_06.htm

8. Moser M, Franklin SS. Hypertension management: results of a new national survey for the hypertension education foundation: Harris interactive. J Clin Hypertens. 2007 May;9(5):316-23.

9. Reis JP, Dubose KD, Ainsworth BE, Macera CA, Yore MM. Reliability and validity of the occupational physical activity questionnaire. Med Sci Sports Exerc. 2005 Dec;37(12):2075-83.

10. Morisky DE, Green LW, Levine DM. Concurrent and predictive validity of a self-reported measure of medication adherence. Med Care. 1986 Jan;24(1):67-74.

11. Grace SL, Barry-Bianchi S, Stewart DE, Rukholm E, Nolan RP. Physical activity behavior, motivational readiness and selfefficacy among Ontarians with cardiovascular disease and diabetes. J Behav Med. 2007 Feb;30(1):21-9. Epub 2006 Nov 16.

12. Quinn RR, Hemmelgarn BR, Padwal RS, et al. The 2010 Canadian Hypertension Education Program recommendations for the management of hypertension: part I blood pressure measurement, diagnosis, and assessment of risk. Can J Cardiol. 2010 May;26(5):241-8.
13. Hackam DG, Khan NA, Hemmelgarn BR, et al. The 2010 Canadian Hypertension Education Program recommendations for the management of hypertension: part 2 therapy. Can J Cardiol. 2010 May;26(5): 249-58.

14. National Heart, Lung, and Blood Institute. The seventh report of the Joint National Committee on prevention, detection, evaluation, and treatment of high blood pressure (JNC7) [Internet]. Bethesda (MD): U.S. Department of Health and Human Services; 2003 [cited 2011 Mar 23]. Available from: http://www.nhlbi.nih .gov/guidelines/hypertension/

15. National Heart, Lung, and Blood Institute. Third report of the Expert Panel on detection, evaluation, and treatment of high blood cholesterol in adults (adult treatment panel III) [Internet]. Bethesda (MD): U.S. Department of Health and Human Services; 2003 [cited 2011 Mar 23]. Available from: http:// www.nhlbi.nih.gov/guidelines/cholesterol/

16. Statistics Canada. Documentation - Survey on Living with Chronic Diseases in Canada - user guide - 2009 [Internet]. 2010 [updated 2011 Nov 29; cited 2011 Apr 12]. Available from: http://www23.statcan.gc.ca/imdb-bmdi /pub/document/5160_D5_T1_V1-eng.htm

17. Canadian Community Health Survey - annual component (CCHS) [Internet]. Ottawa (ON): Statistics Canada; 2010 [updated 2011 Jun 9; cited 2011 Mar 3]. Available from: http: //www.statcan.gc.ca/cgi-bin/imdb/p2SV.pl ?Function $=$ getSurvey \&SDDS $=3226 \&$ lang $=\mathrm{en} \& \mathrm{db}=\mathrm{imdb} \& \mathrm{adm}=8 \& \mathrm{dis}=2$

18. Béland Y. Canadian Community Health Survey - methodological overview. Health Rep. 2002 Mar;13(3):9-14.

19. Desmeules M. Appendix A: overview of National Population Health and Canadian Community Health Surveys. BMC Women's Health. 2004 Aug 24;4(Suppl I):S35.

20. Rao JN. Bootstrap methods for analyzing complex sample survey data. Proceedings of Statistics Canada International Symposium Series. Symposium 2006: Methodological Issues in Measuring Population Health; 2006; catalogue no. 11-522-XIE. 
21. Gee ME, Campbell NR, Gwadry-Sridhar F, et al.; Outcomes Research Task Force of the Canadian Hypertension Education Program. Antihypertensive medication use, adherence, stops and starts in Canadians with hypertension. Can J Cardiol. 2012 May; 28(3):383-9.

22. Hypertension [Internet]. Ottawa (ON): Public Health Agency of Canada; [updated 2009 Dec 10; cited 2011 Mar 29]. Available from: http://www.phac-aspc.gc.ca/cd-mc /slcdcfs-epamccfi/hypertension-eng.php

23. Walker RL, Gee ME, Bancej C, et al. Health behaviour advice from health professionals to Canadian adults with hypertension: results from a national survey. Can $\mathrm{J}$ Cardiol. 2011 Jul-Aug;27(4):446-54.

24. Gee ME, Bienek A, Campbell NRC, et al. Prevalence of, and barriers to, preventive lifestyle behaviours in hypertension (from a national survey of Canadians with hypertension). Am J Cardiol. 2012 Feb;109(4): 570-5.

25. Bancej CM, Campbell N, McKay DW, Nichol M, Walker R, Kaczorowski J. Home blood pressure monitoring among Canadian adults with hypertension: results from the 2009 Survey on Living with Chronic Diseases in Canada. Can J Cardiol. 2010 May;26(5): e152-7.

26. Gee ME, Campbell NR, Bancej CM, et al. Perception of uncontrolled blood pressure and behaviours to improve blood pressure: findings from the 2009 Survey on Living with Chronic Diseases in Canada. J Hum Hypertens. 2011 Mar; 26(3):188-95; doi:10.1038 /jhh.2011.5.

27. Chiu M, Austin PC, Manuel DG, Tu JV. Comparison of cardiovascular risk profiles among ethnic groups using population health surveys between 1996 and 2007. CMAJ. 2010 May;182(8):E301-10.

28. Other reference periods - Survey on Living with Chronic Diseases in Canada (SLCDC) [Internet]. Ottawa (ON): Statistics Canada; 2011 [cited 2011 Mar 22]. Available from: http://www.statcan.gc.ca/cgi-bin/imdb/p2SV .pl? Function $=$ getInstanceList\&SurvId $=38899$ \&SurvVer $=2$ \&InstaId $=38900 \&$ SDDS $=5160$ \&lang $=\mathrm{en} \& \mathrm{db}=\mathrm{imdb} \& \mathrm{adm}=8$ \&dis $=2$
29. Survey on Living with Neurological Conditions in Canada [Internet]. Ottawa (ON): Statistics Canada; 2012 [cited 2012 Apr 13]. Available from: http://www.statcan .gc.ca/survey-enquete/household-menages /5182-eng.htm 